\title{
Energy Simulation Framework Integrated with Green Manufacturing-Enabled PLM Information Model
}

\author{
Wen-Bin Zhao', Jin-Woo Jeong', Sang Do Noh', and John T. Yee',,\# \\ 1 Department of Systems Management Engineering, Sungkyunkwan University, 2066, Seobu-ro, Jangan-gu, Suwon-si, Gyeonggi-do, 400-746, South Korea \\ \# Corresponding Author / E-mail: shangtlee@skku.edu, TEL: +82-31-290-7639, FAX: +82-31-290-7610
}

KEYWORDS: Product lifecycle management (PLM), Information model, Sustainability, Green manufacturing, Energy simulation

\begin{abstract}
Manufacturing industry has been facing tremendous pressure on environmental regulations like the reduction of pollutants, e.g., carbon dioxide. Limited natural resources have driven manufacturing companies to seek ways to reduce energy consumption for daily production. Manufacturing industry needs to consider sustainability for green manufacturing during the entire product life cycle. Conventional product life cycle management has not considered energy consumption with respect to product manufacturing. This paper proposes a new product life cycle management information model by considering the sustainability aspects. And a framework is presented to conduct energy simulation for analyzing the impact of sustainability on manufacturing. Analysis results show that the energy simulation using the sustainability-enabled product life cycle management information model could assist the manufacturing industry to save energy.
\end{abstract}

Manuscript received: November 21, 2014 / Revised: May 8, 2015 / Accepted: May 20, 2015

\section{Introduction}

Whereas industrialization resulted in remarkable growth in economy and industry, it caused many environmental issues and problems along extensive energy consumption around the world. ${ }^{1-3}$ To overcome this global crisis, each country has been seeking diverse solutions, e.g., low-carbon green growth, cleaner production, and environment-friendly products. Especially, under limited resources of the Earth, manufacturers have to make sustainable product development and manufacturing that are the key drivers for future growth. ${ }^{4-6}$ The United Nations World Commission on Environment and Development defined sustainable development as "development that meets the needs of the present without compromising the ability of future generations to meet their own needs."7 Until now, this has been the most widely used explanation of the concept of sustainability.

Green manufacturing is a new paradigm by which manufacturers produce their products using sustainable methods, while maintaining their global competitiveness. The objective of the green manufacturing is to minimize the use of natural resources and reduce the emission of wasting environmental pollutants.

Product Life cycle Management (PLM) is the integrated management of relevant information throughout the product life cycle, from customer needs capture, through product design and engineering, manufacturing, maintenance and service, to disposal. Today's market requires prompt and effective product development and manufacturing that makes companies recognize the importance of PLM. PLM's objective is to minimize cost and time by understanding problems in advance in product development and manufacturing processes, and improve business performance utilizing technology and service support. To accommodate the green manufacturing, PLM needs to be expanded in its scope and structure.

A number of previous studies was found on sustainable PLM and its information model design. Ju Yeon Lee et al., ${ }^{8}$ Natalia Duque Ciceri et al., ${ }^{9}$ Zhen Wang et al., ${ }^{10}$ and Deogratias Kibira et al. ${ }^{11}$ proposed up-todate concepts of PLM for achieving sustainability, and designed corresponding information models. However, these studies only focus on conceptual and theoretical aspects of sustainable PLM and are in lack of sustainability evaluation, having limited information models for managing and applying relevant data as to product sustainability.

Sustainability evaluation could be performed using simulation. Energy simulation virtualizes production environments that use a variety of energy resources and determines desirable, possibly, optimal performance of energy consumption metrics. Pang Xiufeng et al. ${ }^{12}$ and Julien Bouyer et al. ${ }^{13}$ performed studies using energy simulation software, but did not consider sufficient amount of application data.

This study presents a new PLM information model to analyze various environmental regulations and green indicators for green 
manufacturing using the Unified Modeling Language (UML) methodology. In addition, we present an integrated framework that enables to conduct the energy simulation based on the newly designed PLM information model focusing on manufacturing.

\section{Backgrounds}

This section explains foundational means that are needed to develop the integrated framework, which are UML, conventional PLM information model, and energy simulation software.

\subsection{UML Methodology}

UML is a modeling language that is used for requirement analysis, system design, and system implementation. It has been used as an important communication method for object-oriented system development. ${ }^{14,15}$ UML is a method that can easily express the system architecture in detail and confirm the reflection of requirements to the system. An object-oriented system has observed tremendous evolution, and UML has been used as a comprehensive language that models all different aspects of a system. UML is also capable of visualizing, specifying, constructing, and drawing a system graphically, utilizing three modeling methods, namely, structural model, behavioral model, and architectural model. Many software programs have used the UML. ${ }^{16}$ The UML methodology could be applied to other purposes other than software. This study uses the structural model to derive class diagrams and use case diagrams of the PLM information model.

For the purpose of illustrating the UML methodology, Fig. 1 shows an example of vehicle mileage requirements execution given by government. Three actors are involved in meeting the vehicle mileage requirements: company, government, and consumer. The government specifies the requirements of vehicle mileage by sector according to depleted fuel supply. The company, that is, an automotive manufacture, designs and produces vehicles to meet the requirements of the government. The consumer trades off mileage factor with vehicle price and other considerations in purchasing a vehicle. UML assists visualizing mutual relationships among actors using a use case diagram on left and then, establishing a class diagram to understand specifics between actors on right.

\subsection{Conventional PLM Information Model}

PLM information model for manufacturing considers four main attributes, such as, Process, Product, Plant, and Resource (P3R) along with base information of production as shown in Fig. $2 .^{17,18}$ The P3R information model is centered on the manufacturing process, the

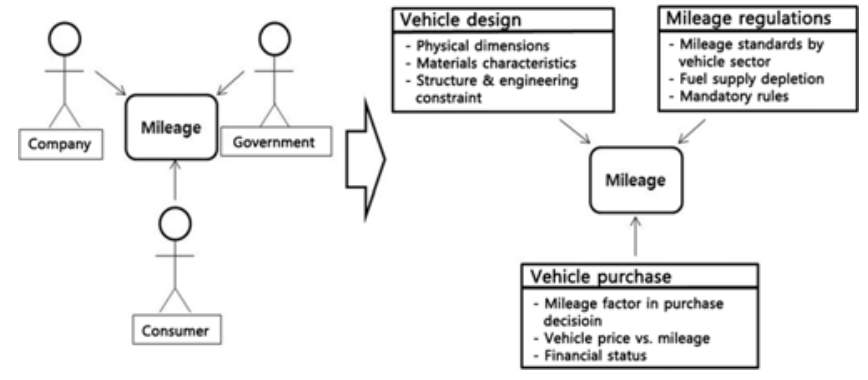

Fig. 1 UML example product produced, the manufacturing resource used, and the manufacturing plant in an integrated manner. To capture green manufacturing aspects, this study includes sustainability portion to the existing P3R information model as shown in a later section. ${ }^{19}$

\subsection{Energy Simulation Software}

Since 1995, diverse energy simulation programs have been developed. The U.S. Department of Energy (DOE) has developed new simulation tools based on the experiences of BLAST and DOE-2 program. Three leading organizations for energy simulation software are the Lawrence Berkeley National Laboratory, the US Army Construction Engineering Laboratory (which developed the DOE-2 program), and the University of Illinois (which developed the BLAST program). Another software, say, EnergyPlus, combined its own new functions with the advantages of BLAST and DOE-2 program. ${ }^{20,21}$ The user interface is not splendid, but the information input and output can be performed using a simple ASCII code, although it is only for the simulation engine that has been opened for developers. Also, EnergyPlus' most significant advantage is easy interfacing with other programs by connecting the module of a specific system. ${ }^{22}$

Loads Features and Capabilities of EnergyPlus are as follows:

- Heat Balance Calculation

Interior Surface Convection

Moisture Absorption/Desorption

Thermal Comfort

Anisotropic Sky Model

Advanced Fenestration Calculations

Daylighting Illumination and Controls

Heating, Ventilation, And Air Conditioning (HVAC) Systems and Equipment Feature

- Fluid Loops

- Air Loops

- User-Configurable HVAC Systems

- Hardwired Template HVAC Systems

- High-Temperature Radiant Heating

- Low-Temperature Radiant Heating/Cooling

- Atmospheric Pollution Calculation

This study uses EnergyPlus energy simulation software program to emulate green manufacturing environment.

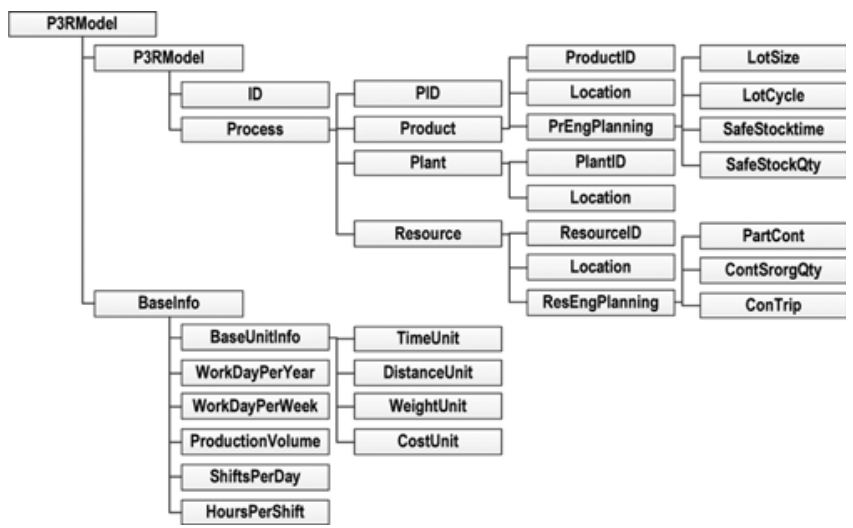

Fig. 2 Conventional PLM information model ${ }^{19}$ 


\section{PLM Information Model for Green Manufacturing}

This section explains the PLM indicators of sustainability and the green manufacturing PLM information model.

\subsection{PLM Indicators for Green Manufacturing}

\subsubsection{Institution of Chemical Engineers Sustainability Indicators}

The Institution of Chemical Engineers (IChemE) in the United Kingdom announced the IChemE sustainability indicator items, which are the sustainable development indicators based on ISO 14001 and the European Eco-Management and Audit Scheme (EMAS). ${ }^{23,24}$ IChemE classified the sustainable development indicator items into environmental performance indicators, economic performance indicators, and social performance indicators. The environmental performance indicators include materials used, emissions, and additional items; the economic performance indicators, the profit, tax, value, and investment; and the social performance indicators, the workplace, society, and culture.

\subsubsection{Global Reporting Initiative Sustainability Indicators}

The Global Reporting Initiative (GRI) is an organization that was founded by the Coalition for Environmentally Responsible Economies (CERES) and the United Nations Environment Program, which are NGOs. ${ }^{25}$ Since 2006, GRI released the final version of sustainability reporting guidelines in 2013. The GRI report is the most frequently used set of sustainability management reporting guidelines in the world, and it deals with sustainability issues among the existing guidelines comprehensively.

The GRI report represents the activities in measurement and disclosure of performance of an organization for sustainable development, and the corresponding responsibilities of internal and external stakeholders. It explains the sustainable management performance of a reporting subject from a balanced and rational standpoint by including both positive and negative effects. The GRI evaluation indicators are classified into the environmental performance indicators, economic performance indicators, and social performance indicators.

\subsubsection{PLM Indicators of Sustainable Development for Green Manufacturing}

This study uses the indicators of sustainable development for green manufacturing as shown in Fig. 3. Choosing the sustainable indicators is the most crucial task of this study. Those indicators should be appropriate for covering all the requirements for green manufacturing. The IChemR report is not comprehensive enough to cover all the necessary sustainability indicators for manufacturing. The GRI report has much more comprehensive coverage with a variety of specific detailed measures. Thus, most of the indicators are taken from the GRI report with a few chosen from the IChemE report. The three types of performance indicators at both reports are suitable for manufacturing industry to reflect sustainability at real production environments. The environmental performance indicators consist of materials used, energy, emissions/pollution, biodiversity, and compliance. The economic performance indicators include investments, economic performance, market presence, and indirect economic effects. Finally, the social performance indicators have labor practices, human rights, social influence, and product responsibility.
Specifically, within the environmental indicators, the materials used include the water, product materials, manufacturing process materials, non-renewable materials, wrapping materials, life cycle of the materials used, amount of environment-friendly wrapping, and physical properties of the materials used. The energy includes the consumption of each non-renewable primary energy source, consumption of each renewable primary energy source, indirect energy consumption, energy conservation through business efficiency, renewable energy utilization ratio, energy utilization ratio per product manufactured, energy cost per product, percentage of the energy cost, and energy efficiency of plant heating and air-conditioning. The emissions/pollution includes the total emission of direct/indirect greenhouse gas, amount of treated greenhouse gas, emission of ozone-depleting substances, air pollutant emission, total waste water emission for each final emission source, purified waste water emission, recycling ratio of squandered water, hazardous waste emission, general waste emission, and waste emission for each form and disposal method. The biodiversity includes the location and size of the land owned, leased, and managed in conservation areas, areas with a high biodiversity value, or surrounding areas. The compliance includes the fines due to the violation of environmental laws and regulations, nonmonetary sanctions, and relevant laws.

For the economic indicators, the investment includes the indirect and direct investment. The economic performance includes the profit, operating cost, employee compensation cost, sum of donations, sum of local community investments, earned surplus, cost of capital, and tax. The market presence includes the local purchase policies of major workplace, procedure for the preferred employment of locals in main workplace, and senior managers who are locals. The indirect economic effect includes the infrastructure investment for public interest and the effect of service support activities.

For the social indicators, the labor practices include the employment, labor-management relations, health and safety of laborers, education and training, and diversity and equal opportunities. The human rights include the investment and procurement practices, discrimination prohibition, freedom of association and collective bargaining, child labor, forced labor, security practices, and rights of natives. The social influence includes the local effects, corruption, public policy, and competition inhibition behavior. The product responsibility includes the customer health and safety, product and service labeling, marketing communication, and protection of customers' personal information.

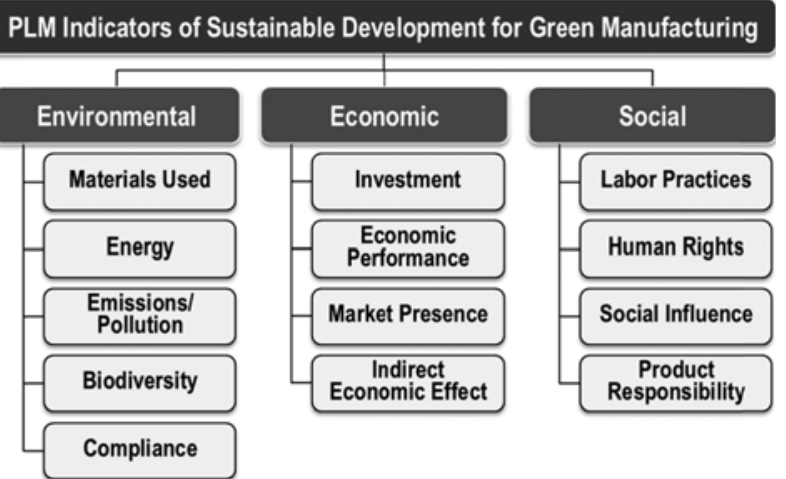

Fig. 3 PLM indicators of sustainable development for green manufacturing 


\subsection{PLM Information Model for Green Manufacturing}

Using the PLM sustainability indicators identified in Fig. 3, we need to further narrow down and specify each element using the UML methodology. The requirements for each element are analyzed using a use case diagram. First, the actors who perform acts in a sustainable system are defined as shown in Fig. 4. The company aspect actor is the company and worker. The social aspect actors are the customer and society. The nation aspect actor is the government and the environmental aspect actor is the Earth and people. ${ }^{17}$
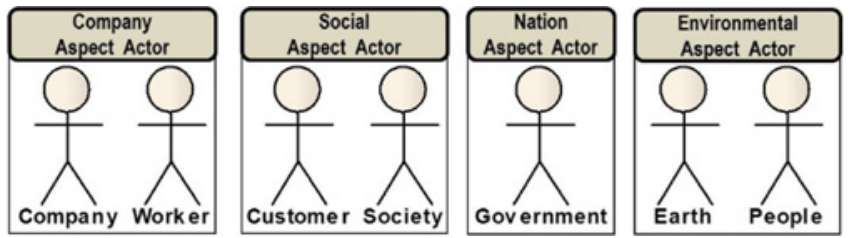

Fig. 4 Definition of use case actors

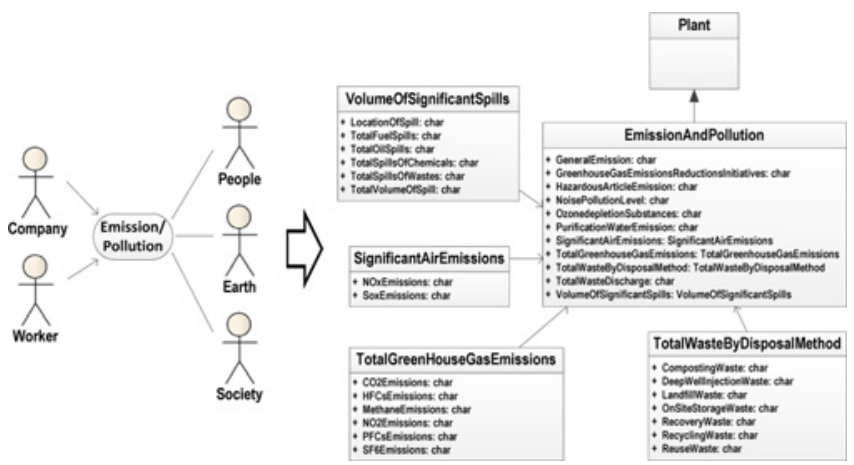

Fig. 5 Example use case diagram and class diagram ${ }^{18}$
As an example, for the "emissions/pollution" element, Fig. 5 shows the results of derived class diagram using the use case analysis. According to the interaction relationships between the actors, the class diagram is developed by specifying detailed attributes entities and super classes of those interactions.

The plant entity in Fig. 5 is further developed to the information model as shown in Fig. 6. The plant entity includes the subclasses of compliance, materials used, biodiversity, energy, and emissions/pollution. Likewise, we can develop the similar information models for other PLM information model components, namely, the process, product, and resource. Fig. 7 compares the conventional P3R information model with the energy-enabled P3RE information model. The P3RE information model adds sustainability information for the process, product, and plant components. Moreover, the P3RE model has the enterprise information of the corresponding company with respect to financial information and environmental regulations and compliance information.

Fig. 8 shows the further details of the P3RE information model with a sample XML data. The "Enterprise" entity has information for company's policies and directions for sustainability, and the "BaseInfo" includes basic information for green production. The "Process" represents the process of product manufacturing with the plant. The information model is transformed to XML format for energy simulation.

\section{Energy Simulation Framework Integrated with PLM Information Model}

Fig. 9 shows the overall framework in which energy simulation is conducted in conjunction with the P3RE information model for green

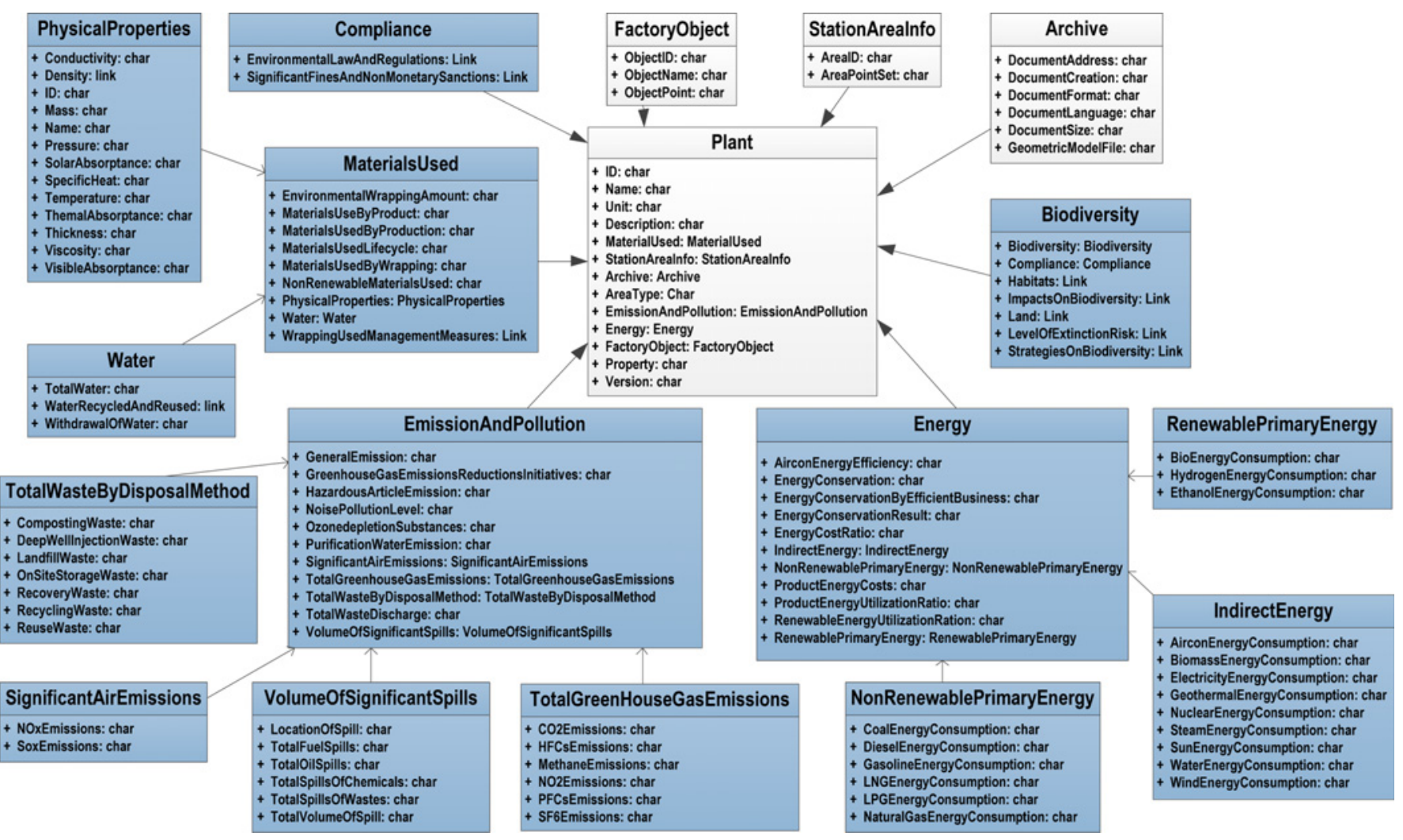

Fig. 6 PLM information model for green manufacturing (plant part) 
manufacturing. The user makes a request through the user interface in the add-in format of Autodesk Revit program. The information library, which serves as the middleware, has the XML data files that map the P3RE information model. The simulation engine runs an energy simulation model using the user inputs and produces the outputs to the user.
Fig. 10 shows the information flow of energy simulation execution. The information obtained by CAD modeling in Autodesk Revit is automatically transformed to an XML file, which is a neutral schema, following the format of the defined P3RE information model. Instead of directly using the input format of EnergyPlus, the neutral XML file is used for extensibility
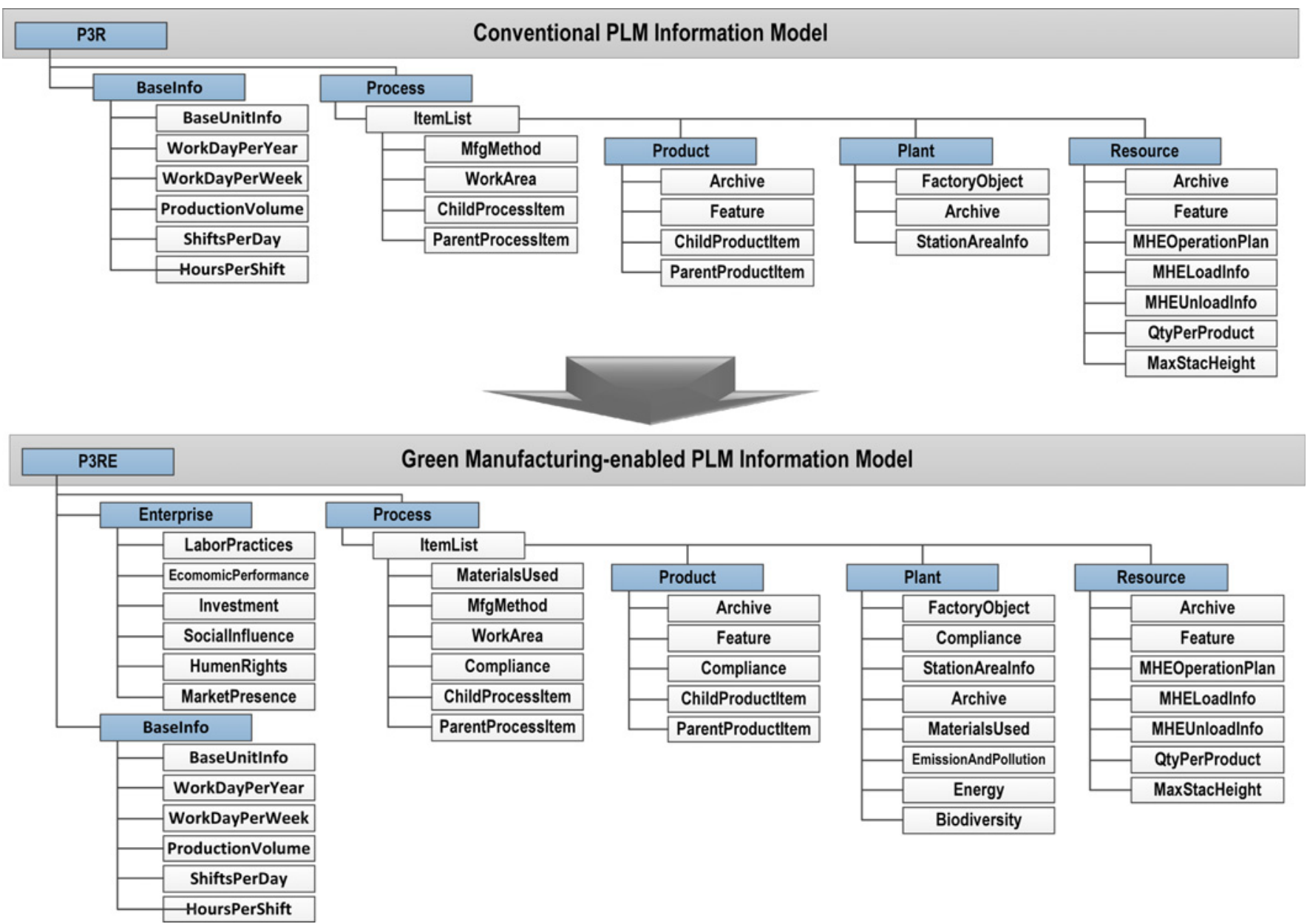

Fig. 7 PLM information model for green manufacturing

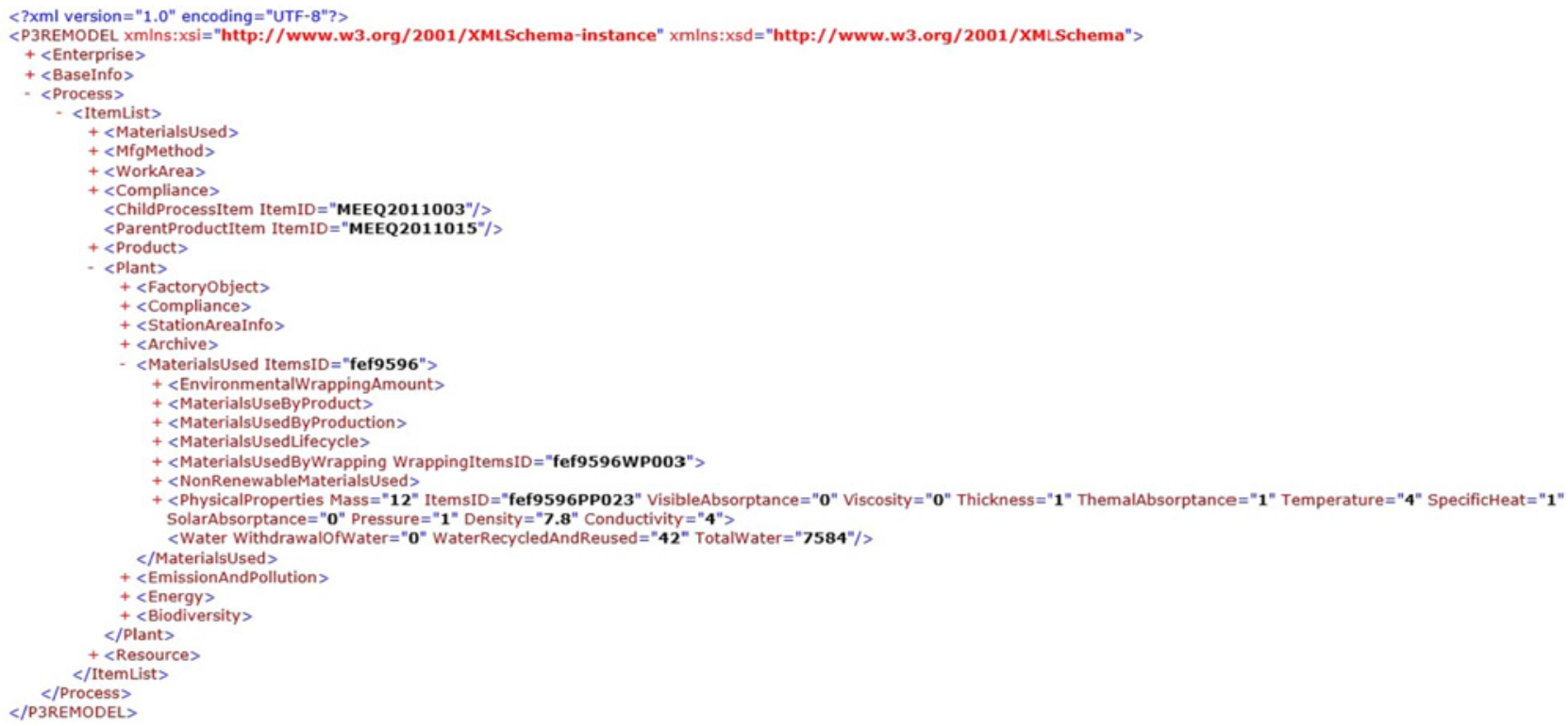

Fig. 8 Sample PLM information model and XML data 
and information interoperability. Also, the XML file is automatically converted to an IDF file, which is the ASCII input format of EnergyPlus and then, energy simulation is performed. In this process, the information entered by the user through the user interface is mapped into the input information of the energy simulation. The user could perform what-if analysis by changing input parameters and see the results accordingly.

\section{A Case Study}

Fig. 11 shows an example plant configuration. The plant has a HVAC system, a ventilation system, and equipment for coating processes. The plant controls the temperature by circulating internal air and bringing in outside air. ${ }^{21}$

Table 1 summarizes the components of the plant that include the building construction, equipment, and HVAC system. Table 2 shows the control variables of energy simulation, such as, the air supply of heating system, the air supply of air-conditioning system, the internal

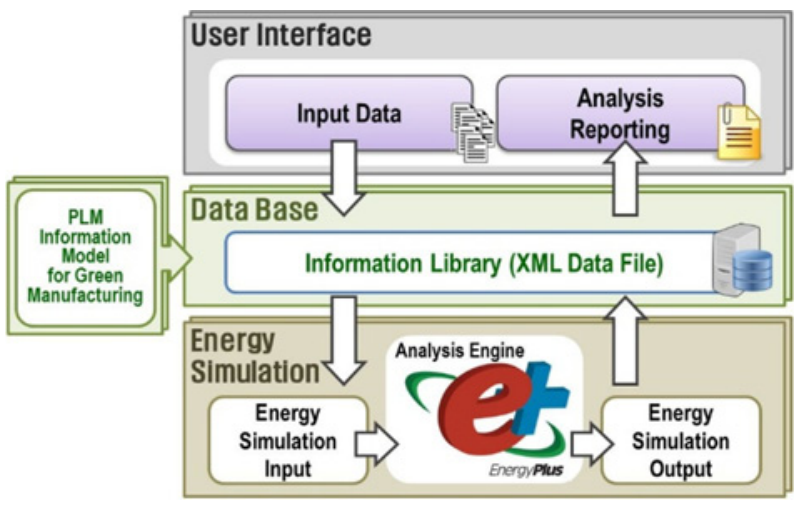

Fig. 9 Energy simulation framework integrated with PLM information model

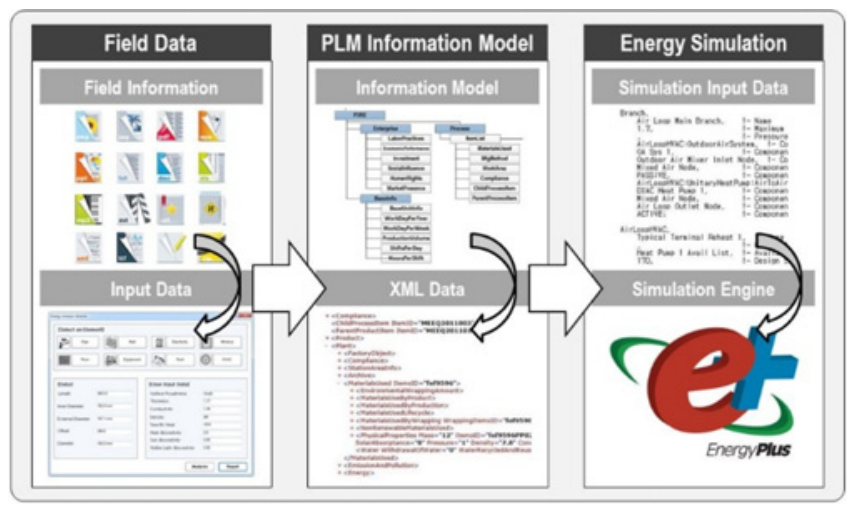

Fig. 10 Information flow

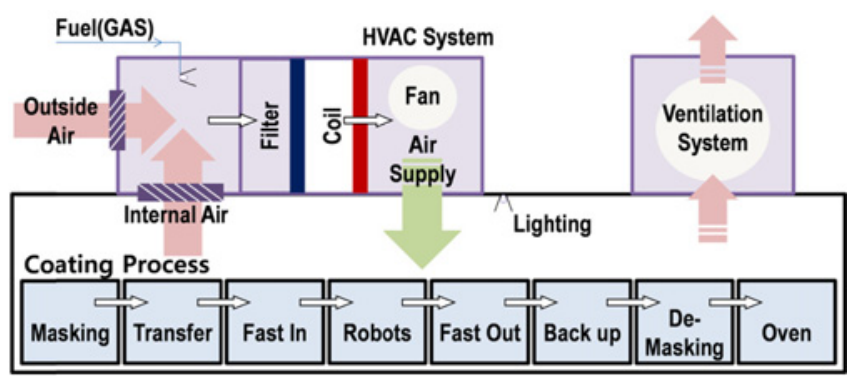

Fig. 11 Example plant configuration air emission of ventilation system, and the outside air suction of HVAC system. For each of energy source objects, the minimum and the maximum are given by reflecting real practices of the plant.

Fig. 12 shows the interactions among the objects of simulation.

For the case plant, energy simulation is conducted as follows:

(1) A user performs the CAD modeling of the plant with Autodesk Revit and enters the input information for each element object using the add-in module,

(2) The user enters other input information for process, product, resource, and enterprise, which has been defined by the P3RE information model,

(3) Simulation engine runs the simulation model using the plant operating schedule and other environmental and economic information,

(4) Simulation engine produces outputs,

(5) The outputs are sent to the user through user interface.

To evaluate the energy consumption through the change of operating practices of the HVAC system in the plant, simulation was performed based on the following three scenarios. The simulation is characterized by partially irregular and noisy change over time. We need to iteratively improve the simulation results with a given measure

Table 1 Plant components

\begin{tabular}{|c|c|c|c|c|}
\hline $\begin{array}{c}\text { Plant } \\
\text { component }\end{array}$ & \multicolumn{3}{|c|}{ Type } & $\begin{array}{c}\text { Quantity } \\
\text { (ea) }\end{array}$ \\
\hline \multirow{6}{*}{$\begin{array}{l}\text { Building } \\
\text { construction }\end{array}$} & \multicolumn{2}{|c|}{ Wall } & Ferroconcrete & 6 \\
\hline & \multicolumn{2}{|c|}{ Floor } & Ferroconcrete & 1 \\
\hline & \multicolumn{2}{|c|}{ Roof } & Ferroconcrete & 1 \\
\hline & \multirow{3}{*}{\multicolumn{2}{|c|}{ Pipe }} & Gas pipe & 7 \\
\hline & & & Air pipe & 6 \\
\hline & & & Water pipe & 4 \\
\hline \multirow{4}{*}{ Equipment } & \multirow{2}{*}{\multicolumn{2}{|c|}{ Electrical installation }} & Lighting & 202 \\
\hline & & & Etc. & 2 \\
\hline & \multirow{2}{*}{$\begin{array}{l}\text { Machine } \\
\text { equipment }\end{array}$} & Gas & Oven & 3 \\
\hline & & Electricity & Etc. & 74 \\
\hline \multirow{4}{*}{$\begin{array}{l}\text { HVAC } \\
\text { system }\end{array}$} & \multirow{2}{*}{ Water-Air } & Heating & Direct heating & 1 \\
\hline & & Cooling & Cooling system & 1 \\
\hline & \multicolumn{2}{|c|}{ Ventilation system } & Fan & 9 \\
\hline & \multicolumn{2}{|c|}{ Etc. } & Schedule & 5 \\
\hline
\end{tabular}

Table 2 Plant control variables

\begin{tabular}{cccc}
\hline Object & Variables & Min. & Max. \\
\hline Heating system & Air supply $\left(\mathrm{m}^{3} / \mathrm{s}\right)$ & 5 & 7 \\
\hline $\begin{array}{c}\text { Air-Conditioning } \\
\text { system }\end{array}$ & Air supply $\left(\mathrm{m}^{3} / \mathrm{s}\right)$ & 5 & 13 \\
\hline $\begin{array}{c}\text { Ventilation } \\
\text { system }\end{array}$ & Outside air suction $\left(\mathrm{m}^{3} / \mathrm{s}\right)$ & 1 & 3,140 \\
\cline { 2 - 4 } & Internal air emission $\left(\mathrm{m}^{3} / \mathrm{s}\right)$ & 11 & 9 \\
\hline
\end{tabular}

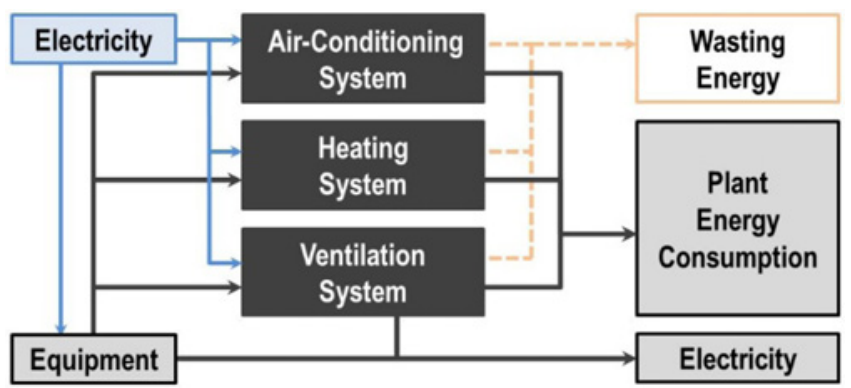

Fig. 12 Interactions between objects 
of quality. The particle swarm optimization algorithm, one of the metaheuristics, was used to optimize the results. Scenario 1 reflects the current operating practices, in other words, no energy consumption was considered. Scenario 2 represents the case when sustainability is considered using the same P3RE information model during the entire year. Scenario 3 considers different sustainability parameters to see the difference in energy consumption according to varying seasons. For each scenario, twenty simulation runs were conducted to reduce random effects. The simulation model was tested and calibrated in conjunction with real practices to ensure its reliability and accuracy with statistical significance, and initial warmup outputs were truncated to keep the steady state accuracy. Table 3 shows the analysis results for each energy source object for each scenario. All the equipment of the plant is operated from $6 \mathrm{am}$ to $11 \mathrm{pm}$. As expected, scenario 1 produced the highest average amount of air supply, suction, and emission per second overall. Scenarios 2 and 3 resulted in lower average amount compared to scenario 1 . And scenario 3 generated more heating during the winter time and more air conditioning during the summer time.

Table 4 summarizes the daily energy consumption converted to Gigajoule (GJ) for each energy source for three scenarios. The total energy consumption was 7,230 GJ per day for scenario 1, 5,740 GJ per day for scenario 2 , and 5,340 GJ per day for scenario 3. The energy consumption of scenario 2 was about $21 \%$ lower than that of scenario 1 , and the energy consumption of scenario 3 was about $27 \%$ lower than that of scenario 1 . Conclusively, scenario 3 resulted in the lowest energy consumption overall, even though it has variations by season.

\section{Managerial Implications}

The energy simulation in conjunction with the P3RE information model provides management with several benefits. First, through energy simulation, we could see the magnitude of energy savings when we pursue green manufacturing by considering the sustainability indicators. Emulating energy resources with regard to the P3RE information model objects could determine specific areas that we could reduce energy consumption. Then, the management could focus on those areas and take proper follow-up actions to achieve actual savings accordingly.

Table 4 Scenario specific energy usage per day

\begin{tabular}{cccc}
\hline Energy consumption (GJ) & Scenario 1 & Scenario 2 & Scenario 3 \\
\hline Heating system (GJ) & 2,460 & 3,520 & 2,140 \\
\hline Air-conditioning system (GJ) & 3,950 & 1,200 & 1,150 \\
\hline Ventilation system (GJ) & 820 & 1,105 & 2,050 \\
\hline Total energy consumption (GJ) & 7,230 & 5,740 & 5,340 \\
\hline $\begin{array}{c}\text { Total energy consumption } \\
\text { (compared to scenario 1) }\end{array}$ & 1 & 0.79 & 0.73 \\
\hline $\begin{array}{c}\text { Growth rate } \\
\text { (compared to scenario 1) }\end{array}$ & $0 \%$ & $-21 \%$ & $-27 \%$ \\
\hline
\end{tabular}

Second, the P3RE information model already defined specific sustainability elements and the energy simulation model utilizes those elements for analyzing energy consumption metrics. The energy simulation framework running with the P3RE information model makes the entire process of analyzing the impact of sustainability for green manufacturing easier. Otherwise, it would require much time and effort to conduct such an analysis.

Third, the energy simulation helps detect and resolve potential issues and problems prior to actual implementation of energy saving strategies or practices and moreover, achieve gradual reduction of energy consumption heading toward determination of operating settings for the lowest or minimum energy consumption.

Fourth, the energy simulation helps the management choose the best alternative by conducting scenario analysis. In addition, the management would be able to set a desirable future performance target in a realistic manner by capturing the current practices. As mentioned in Herrmann et al., ${ }^{26}$ manufacturing companies need to consider sustainability as a selection perspective for the factory of the future.

\section{Conclusions}

This study has presented an energy simulation framework that is equipped with a sustainability-enabled PLM information model. The energy simulation analyzes various green manufacturing indicators and produces the difference in energy consumption metrics before and after considering sustainability. By so doing, we could estimate the impact of energy control and management on actual energy consumption. The case example has shown the analysis results by considering three scenarios. Based on the simulation results, companies could establish and implement realistic strategies that are compliant to energy regulations and policies. This study is somewhat limited in capturing all the other components of PLM by only focusing on green manufacturing with environmental performance indicators.

As a further study, we could pursue real-time decision making by connecting the framework with Enterprise Resource Planning (ERP) system or Manufacturing Execution System (MES). Moreover, we could extend the scope of manufacturing sustainability to other business areas like transportation, logistics by including third party business partners. For this case, the PLM information model needs to be expanded as well.

\section{ACKNOWLEDGEMENT}

This work (NRF-2013R1A2A2A03068143) was supported by Midcareer Researcher Program through NRF (National Research Foundation of Korea) grant funded by the Ministry of Education, Korea.

Table 3 Analysis results

\begin{tabular}{cccccccc}
\hline \multirow{2}{*}{ Object } & \multirow{2}{*}{ Variables } & \multirow{2}{*}{ Scenario 1} & \multirow{2}{*}{ Scenario 2} & \multicolumn{3}{c}{ Scenario 3 } \\
\cline { 5 - 9 } & & & & Spring & Summer & Autumn & Winter \\
\hline Heating system & Air supply $\left(\mathrm{m}^{3} / \mathrm{s}\right)$ & 7 & 6 & 6 & 6 & 6 \\
\hline Air-conditioning system & Air supply $\left(\mathrm{m}^{3} / \mathrm{s}\right)$ & 13 & 6 & 6 & 12.650 & 8.205 \\
\hline \multirow{2}{*}{ Ventilation system } & Outside air suction $\left(\mathrm{m}^{3} / \mathrm{s}\right)$ & 2.260 & 1.050 & 3.203 & 2.052 & 4.200 & 4.900 \\
\cline { 2 - 9 } & Internal air emission $\left(\mathrm{m}^{3} / \mathrm{s}\right)$ & 9 & 12 & 20 & 11 & 12 & 18 \\
\hline
\end{tabular}




\section{REFERENCES}

1. Jayal, A. D., Badurdeen, F., Dillon, O. W., and Jawahir, I. S., "Sustainable Manufacturing: Modeling and Optimization Challenges at the Product, Process and System Levels," CIRP Journal of Manufacturing Science and Technology, Vol. 2, No. 3, pp. 144-152, 2010.

2. Lee, G.-B., Ko, M.-J., and Ku, T.-J., "Analysis of Energy Efficiency in PCB Manufacturing Process," Int. J. Precis. Eng. Manuf., Vol. 13, No. 7, pp. 1215-1220, 2012

3. Jo, H., Noh, S. D., and Cho, Y., "An Agile Operations Management System for Green Factory,” Int. J. Precis. Eng. Manuf.-Green Tech., Vol. 1, No. 2, pp. 131-143, 2014.

4. National Council for Advanced Manufacturing, "Sustainable Manufacturing," http://www.nacfam.org/PolicyInitiatives/Sustainable Manufacturing/tabid/64/Default.aspx (Accessed 11 December 2013)

5. Forestry Commission of Great Britain, "Sustainability," http:// www.forestry.gov.uk/forestry/edik-59fmzf (Accessed 7 March 2013)

6. Beng, L. G. and Omar, B., "Integrating Axiomatic Design Principles into Sustainable Product Development,” Int. J. Precis. Eng. Manuf.Green Tech., Vol. 1, No. 2, pp. 107-117, 2014.

7. World Commission on Environment and Development, "Report of the World Commission on Environment and Development: Our Common Future," Oxford University Press, 1987.

8. Lee, J. Y., Kang, H. S., and Noh, S. D., "Simulation-Based Analysis for Sustainability of Manufacturing System," Int. J. Precis. Eng. Manuf., Vol. 13, No. 7, pp. 1221-1230, 2012.

9. Ciceri, N. D., Garetti, M., and Terzi, S., "Product Life Cycle Management Approach for Sustainability," Proc. of the $19^{\text {th }}$ CIRP Design Conference, p. 147, 2009.

10. Zhen, W., Lifeng, W., Yuxiang, R., and Congxin, L., "Research on PLM Multidimensional Data Model,” IET International Conference, pp. 1499-1504, 2006.

11. Kibira, D. and McLean, C., "Modeling and Simulation for Sustainable Manufacturing," Proc. of the $2^{\text {nd }}$ International Association of Science and Technology for Development, p. 254, 2008.

12. Pang, X., Prajesh, B, Zheng, O., Philip, H., Michael, W., and Trevor, B., "Real-Time Building Energy Simulation Using Energyplus and the Building Controls Virtual Test Bed," Proc. of the $12^{\text {th }}$ International Building Performance Simulation Association, pp. 2890-2896, 2011.

13. Bouyer, J., Inard, C., and Musy, M., "Microclimatic Coupling as a Solution to Improve Building Energy Simulation in an Urban Context," Energy and Buildings, Vol. 43, No. 7, pp. 1549-1559, 2011.

14. Wikipedia, "Unified Modeling Language," http://en.wikipedia.org/ wiki/Unified_Modeling_Language (Accessed 8 March 2013)

15. Thimm, G., Lee, S., and Ma, Y.-S., "Towards Unified Modelling of Product Life-Cycles," Computers in Industry, Vol. 57, No. 4, pp. 331-341, 2006.
16. Chun, B. S., “UML Essence,” WOW Books, 2011.

17. Zhao, W. B., Park, Y. H., Lee, H. Y., Jun, C. M., and Noh, S. D., "Design and Implementation of a PLM System for Sustainable Manufacturing," Proc. of the International Conference on Product Life cycle Management, 2012.

18. Zhao, W. B. and Noh, S. D., "A Study on Concept Design of a PLM System for Sustainable Engineering," Proc. of CAD/CAM Annual Conference, 2012

19. Canetta, L., Redaelli, C., and Flores, M., "Digital Factory for Human-Oriented Production System,” Springer, pp. 59-72, 2011.

20. U.S. Department of Energy, "EnergyPlus Energy Simulation Software," http://apps1.eere.energy.gov/buildings/energyplus/ (Accessed 24 December 2013)

21. Lee, E., Jeong, J. W., Zhao, W. B., and Noh, S. D., “A Study on the Effective Operation of HVAC Systems on Manufacturing Plants by EnergyPlus and PSO Algorithm," Transactions of the Society of CAD/CAM Engineers, Vol. 18, No. 2, pp. 120-128. 2013.

22. Zhao, W. B., Jeong, J. W., Lee, H. Y., Noh, S. D., Jo, H. J., et al., “A Study on Development of an Energy Efficiency Evaluation Module for Equipments and Pipes in Early Design Stage of Plant Engineering," Proc. of KSPE Spring Conference, 2012.

23. IChemE, "The Sustainability Metrics: Sustainable Development Progress Metrics Recommended for Use in the Process Industries, Institution of Chemical Engineers," http://nbis.org/nbisresources/ metrics/triple_bottom_line_indicators_process_industries.pdf (Accessed 4 December 2013)

24. Labuschagne, C., "Sustainable Project Life Cycle Management: Criteria for the South African Process Industry," M.Sc. Thesis, Industrial Engineering, University of Pretoria, 2002.

25. Global Reporting Initiative, "Sustainability Reporting Guidelines," https://www.globalreporting.org/Pages/resource-library.aspx (Accessed 12 December 2013)

26. Herrmann, C., Schmidt, C., Kurle, D., Blume, S., and Thide, S., "Sustainability in Manufacturing and Factories of the Future," Int. J. Precis. Eng. Manuf.-Green Tech., Vol. 1, No. 4, pp. 283-292, 2014. 